\title{
Nitrogen and Chlorine Hyperfine Structure in the Rotational Spectra of 4-Chloropyridine
}

\author{
N. Heineking and $\mathrm{H}$. Dreizler \\ Abteilung Chemische Physik im Institut für Physikalische Chemie der Universität Kiel
}

Z. Naturforsch. 41 a, $1297-1301$ (1986); received July 3, 1986

We resolved and analysed the ${ }^{14} \mathrm{~N}$ hyperfine structure in addition to the ${ }^{35} \mathrm{Cl}$ and ${ }^{37} \mathrm{Cl}$ hyperfine structure of 4-chloropyridine- $\left[{ }^{35} \mathrm{Cl}\right]$ and $-\left[{ }^{37} \mathrm{Cl}\right]$ to investigate substitutional effects.

The ${ }^{14} \mathrm{~N},{ }^{35} \mathrm{Cl}$, and ${ }^{37} \mathrm{Cl}$ hyperfine structure in the rotational spectra of 4-chloropyridine- $\left[{ }^{35} \mathrm{Cl}\right]$ and $-\left[{ }^{37} \mathrm{Cl}\right]$ has been investigated by microwave Fourier transform (MWFT) spectroscopy [1]. The aim was to study the substitutional effect produced by the chlorine atom reflected by the ${ }^{14} \mathrm{~N}$ quadrupole coupling. This paper is the second in a series. In the first we presented results for pyridine and [4-D]pyridine [2], which were investigated to provide a reference.

4-Chloropyridine was first investigated by Caminati and Forti [3]. They reported the rotational constants of both isotopic forms and the ${ }^{35} \mathrm{Cl}$ quadrupole coupling constants.

Our MWFT spectrometers in the range from 5.3 to $18 \mathrm{GHz}$ described elsewhere [4-6] were used.

The substance, which at room temperature tends to dimerize, was prepared by neutralisation of 4-chloropyridine hydrochloride (Fluka). It was purified by sublimation and stored below its freezing point of $-42.5^{\circ} \mathrm{C}$.

The spectra were recorded at temperatures of approximately $-35^{\circ} \mathrm{C}$ and pressures between 0.2 and $1 \mathrm{~Pa}$ (1.5 and $7.5 \mathrm{mTorr}$ ).

Part of the measurements are given in Tables $1 \mathrm{a}$ and $1 \mathrm{~b}$. The complete list is available under the number TNA5 from the Universitätsbibliothek, D-2300 Kiel. The multiplets were simulated by a line contour analysis [7] to account for interference of neighbouring lines. A sample of a multiplet is presented in Fig. 1, showing the $\mathrm{Cl}$ and $\mathrm{N}$ hfs of the $4_{23}-3_{22}$ rotational transition of the ${ }^{37} \mathrm{Cl}$-species.

Reprint requests to Prof. Dr. H. Dreizler, Abteilung Chemische Physik im Institut für Physikalische Chemie der Christian-Albrechts-Universität Kiel, Olshausenstr. 40, D-2300 Kiel 1.
A first order hfs analysis [8] proved to be sufficient as the hfs patterns could be calculated near to the experimental uncertainty. A coupled basis $F_{1}=J+I$ (chlorine), $F=F_{1}+I$ (nitrogen), $(J$ angular momentum, $I$ spin operator), was used. The hypothetical unsplit transitions were calculated by
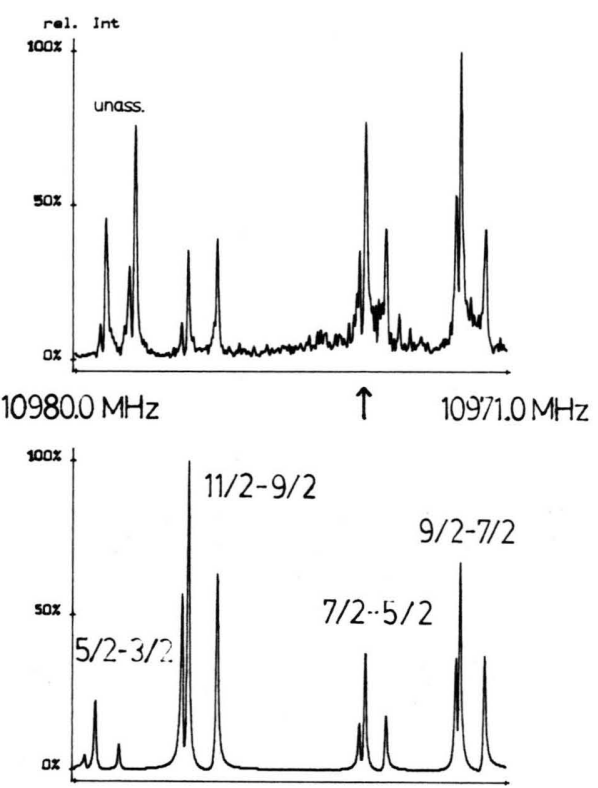

Fig. 1. Rotational transition $J_{K_{-} K_{+}}=4_{23}-3_{22}$ of 4-chloropyridine- $\left[{ }^{37} \mathrm{Cl}\right]$ showing both chlorine and nitrogen hfs. $F_{1}$ quantum numbers are given. The components with $F_{1}=5 / 2-3 / 2$ could not be detected. They are overlayed by an unassigned line. In the lower trace the result of a theoretical line pattern is given. The intensities are not reproduced as the polarization conditions vary over the range of the multiplet. Range $10971-10980 \mathrm{MHz}$ out of a $25 \mathrm{MHz}$ recording, sampling interval $20 \mathrm{~ns}$, polarizing frequency $10974 \mathrm{MHz}(\uparrow)$, temperature $-30^{\circ} \mathrm{C}$, pressure $2.7 \mathrm{mTorr}, 10^{7}$ averaging cycles, 1024 data points supplemented by 3072 zeros prior to Fourier transformation. 
Table 1a. Selection of measured rotational transitions of 4-chloropyridine- $\left[{ }^{35} \mathrm{Cl}\right]$ showing ${ }^{35} \mathrm{Cl}\left(F_{1}\right.$ quantum numbers) and ${ }^{14} \mathrm{~N}(F$ quantum numbers) hyperfine structure. The $F$ and $F_{1}$ quantum numbers are multiplied by $2 . v$ measured and improved frequencies, $\Delta v$ hfs splittings referred to the strongest component, $v_{0}$ hypothetical unsplit lines, $\Delta(\Delta v)=\Delta v-\Delta v_{\text {calc }}$ deviations of the splittings, $\Delta v_{\text {calc }}$ splittings calculated with the constants of Table 2 , $\Delta v_{0}$ deviations from $v_{0}$ hypothetical unsplit lines, $\Delta(\Delta v)=\Delta v-\Delta v_{\text {calc }}$ deviations of the splittings, $\Delta v_{\text {calc }}$ splittings calculated with the cons
the rigid rotor spectrum calculated with the rotational constants of Table 2 , determined from transitions marked with *.

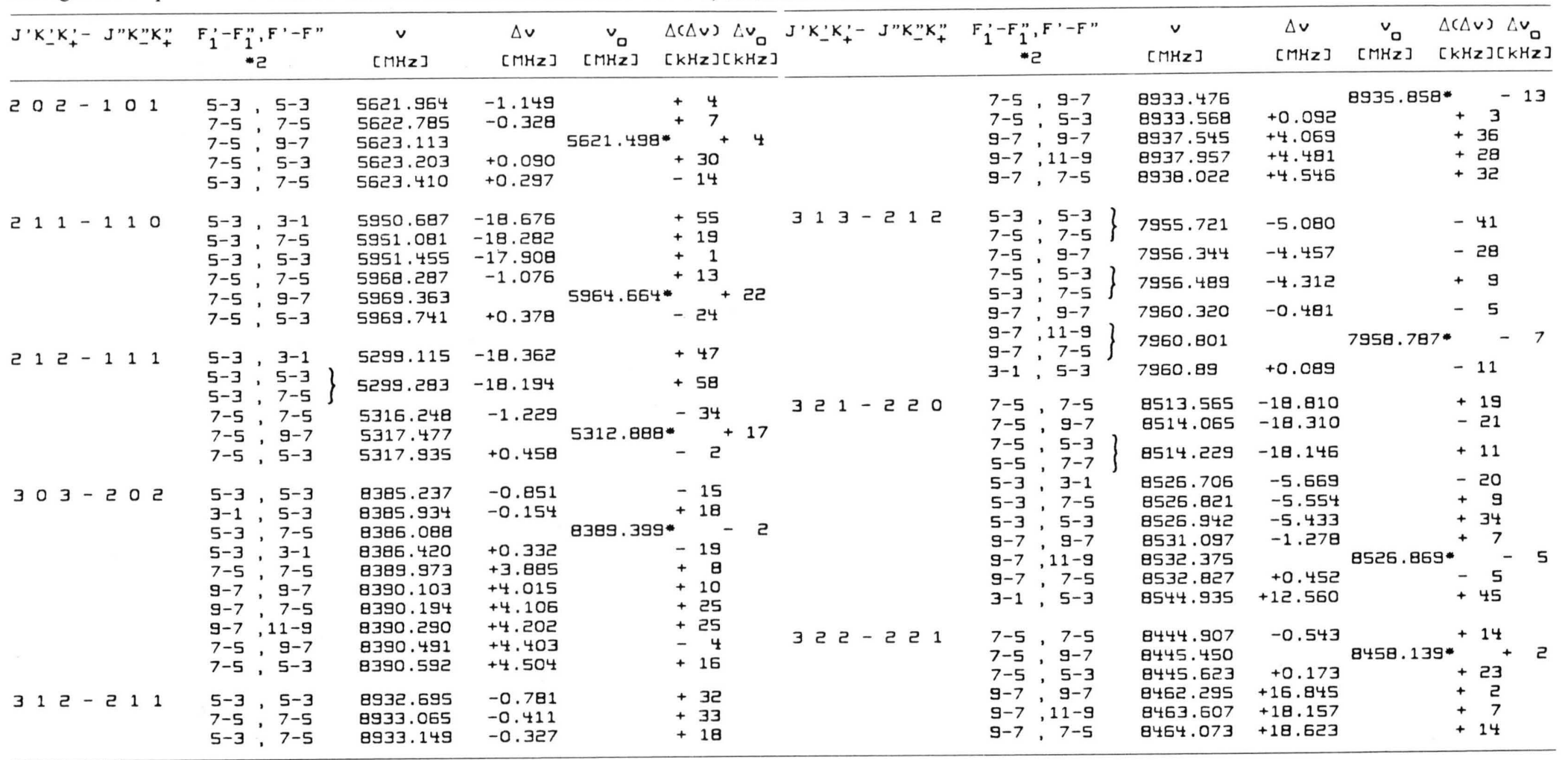


Table $1 \mathrm{~b}$. Selection of measured rotational transitions of 4-chloropyridine- $\left[{ }^{37} \mathrm{Cl}\right]$ showing ${ }^{37} \mathrm{Cl}\left(F_{1}\right.$ quantum numbers) and ${ }^{14} \mathrm{~N}(F$ quantum numbers) hyperfine structure. See also Table 1 a.

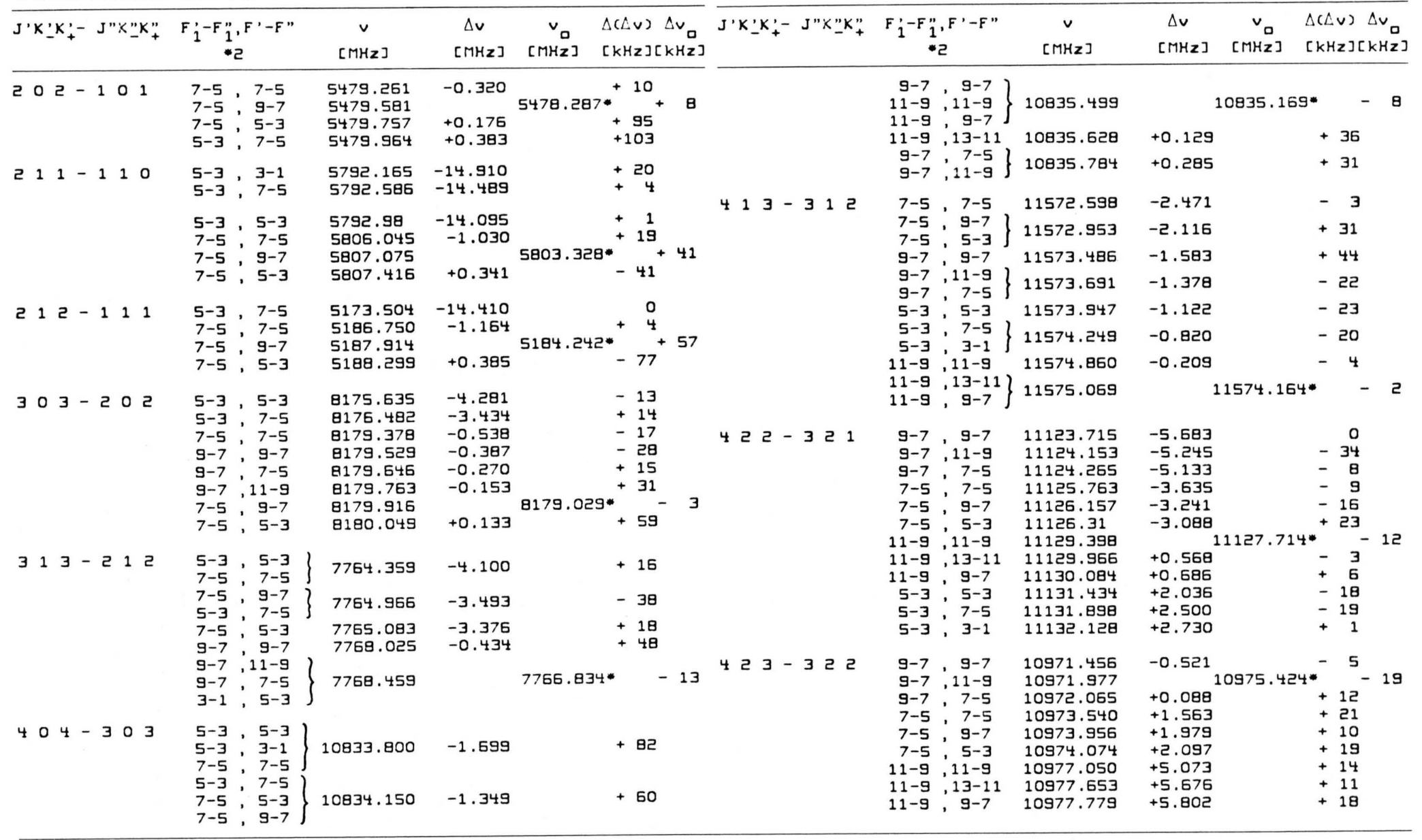


Table 2. Rotational and quadrupole coupling constants $[\mathrm{MHz}]$ of 4-chloropyridine- $\left[{ }^{35} \mathrm{Cl}\right]$ and $-\left[{ }^{37} \mathrm{Cl}\right]$ determined from all measured transitions. $\sigma$ standard deviation of the fit in $\mathrm{kHz},|(B, C)|$ maximum correlation coefficient. Single standard errors in brackets. Derived parameters below the line.

\begin{tabular}{lclc}
\hline \multicolumn{2}{l}{ 4-chloropyridine- $\left[{ }^{35} \mathrm{Cl}\right]$} & \multicolumn{2}{l}{ 4-chloropyridine- $\left[{ }^{37} \mathrm{Cl}\right]$} \\
\hline$A$ & $6019.0(4)$ & $A$ & $6019.1(7)$ \\
$B$ & $1572.631(2)$ & $B$ & $1528.210(5)$ \\
$C$ & $1246.748(2)$ & $C$ & $1218.659(6)$ \\
$\sigma$ & 14 & $\sigma$ & 31 \\
$|(B, C)|$ & 0.792 & $|(B, C)|$ & 0.833 \\
$\chi_{a a}\left({ }^{35} \mathrm{Cl}\right)$ & $-71.65(2)$ & $\chi_{a a}(37 \mathrm{Cl})$ & $-56.4(1)$ \\
$\chi_{b b}\left({ }^{35} \mathrm{Cl}\right)$ & $+39.25(11)$ & $\chi_{b b}\left({ }^{37} \mathrm{Cl}\right)$ & $+30.8(3)$ \\
$\chi_{a a}(\mathrm{~N})$ & $-4.81(1)$ & $\chi_{a a}(\mathrm{~N})$ & $-4.7(1)$ \\
$\chi_{b b}(\mathrm{~N})$ & $+1.64(4)$ & $\chi_{b b}(\mathrm{~N})$ & $+1.5(1)$ \\
$\sigma$ & 15 & $\sigma$ & 34 \\
$\left.\mid \chi_{a a}(\mathrm{Cl}), \chi_{b b}(\mathrm{Cl})\right) \mid$ & 0.197 & $\left|\left(\chi_{a a}(\mathrm{~N}), \chi_{b b}(\mathrm{~N})\right)\right|$ & 0.303 \\
\hline$\chi_{c c}\left({ }^{35} \mathrm{Cl}\right)$ & $+32.40(11)$ & $\chi_{c c}\left({ }^{37} \mathrm{Cl}\right)$ & $+25.6(3)$ \\
$\chi_{c c}(\mathrm{~N})$ & $+3.17(4)$ & $\chi_{c c}(\mathrm{~N})$ & $+3.2(1)$ \\
\hline
\end{tabular}

adding the hfs corrections to the frequencies of the strongest multiplet components. The transitions marked by asterisks were used for a rigid rotor analysis to refine the rotational constants. This refinement did not influence the hfs analysis.

The rotational and quadrupole coupling constants are given in Table 2. The standard errors of the rotational constants of the ${ }^{37} \mathrm{Cl}$-species are higher as lines with higher $J$ had to be included in the fit.

The coupling constants of the ${ }^{37} \mathrm{Cl}$ isotopomer are determined less precise. This reflects the lower isotopic abundance. Within the single standard error there is a rough agreement of the nitrogen coupling constants. We used the programs Q2SIM [9] and Q2FIT [10] for the hfs and DH9 [11] for the rotational analysis. The results for the nitrogen coupling will be discussed in a forthcoming paper.

\section{Chlorine Coupling Discussion}

The interpretation of the chlorine quadrupole coupling constants is guided by the Townes-Dailey approach [12]. It is assumed that the $\mathrm{C}-\mathrm{Cl}$ bond is formed by a partially s-hybridized $3 \mathrm{p}_{z}$ orbital, the two counterhybridized lone pair orbitals in the molecular plane being equivalent. The $\mathrm{p}_{y}$ orbital perpendicular to the pyridine ring is further supposed to interfere with the $\pi$ orbitals of the aromatic system, lowering its occupation and forming a partial double bond.

The ionic character $i_{\sigma}$ of the $\mathrm{C}-\mathrm{Cl}$ bond and the double bond charater $i_{\pi}$ serve as determinable variables. The hybridization parameter $a_{\mathrm{s}}^{2}$ is assumed to be $15 \%$ [13] for the $\mathrm{C}-\mathrm{Cl}$ bond.

The four valence orbitals are described by

$\psi_{1}(\sigma$ bond $)=a_{\mathrm{s}} \psi_{\mathrm{s}}+\left(1-a_{\mathrm{s}}^{2}\right)^{1 / 2} \psi_{\mathrm{p}_{z}}$,

$\psi_{2,3}$ (lone pair orbitals)

$$
=\left(\frac{1}{2}-\frac{1}{2} a_{\mathrm{s}}^{2}\right)^{1 / 2} \psi_{\mathrm{s}} \pm\left(\frac{1}{2}\right)^{1 / 2} \psi_{\mathrm{p}_{z}}-\left(\frac{1}{2} a_{\mathrm{s}}^{2}\right)^{1 / 2} \psi_{\mathrm{p}_{z}},
$$

$\psi_{4}(\pi$ bonding orbital $)=\psi_{p_{v}}$.

The occupation numbers are

$$
\begin{aligned}
& n_{1}=1+i_{\sigma}, \\
& n_{2}=n_{3}=2, \\
& n_{4}=2-i_{\pi} .
\end{aligned}
$$

From (1) and (2)

$$
\begin{aligned}
& n_{x}=2, \\
& n_{y}=2-i_{\pi}, \\
& n_{z}=1+i_{\sigma}+a_{\mathrm{s}}^{2}\left(1-i_{\sigma}\right),
\end{aligned}
$$

result.

The independent coupling constants may then be expressed by

$\chi_{z z}=\chi_{a a}=\left[\left(i_{\sigma}-1\right)\left(1-a_{\mathrm{s}}^{2}\right)+\frac{1}{2} i_{\pi}\right] e Q q_{310}$,

$\chi_{x x}=\chi_{b b}=\left[-\frac{1}{2}\left(i_{\sigma}-1\right)\left(1-a_{\mathrm{s}}^{2}\right)+\frac{1}{2} i_{\pi}\right] e Q q_{310}$.

It should be noted that the $\mathrm{C}-\mathrm{Cl}$ bond is parallel to the principal inertia axis $a$. From (4) we get

$$
\begin{aligned}
& i_{\pi}=\frac{2}{3} \frac{\left(\chi_{a a}+2 \chi_{b b}\right)}{e Q q_{310}}, \\
& i_{\sigma}=1+\frac{2}{3} \frac{\left(\chi_{a a}-\chi_{b b}\right)}{e Q q_{310}\left(1-a_{\mathrm{s}}^{2}\right)} .
\end{aligned}
$$

With the experimental data of Table 2 and

$$
e Q q_{310}\left({ }^{35} \mathrm{Cl}\right)=+109.74 \mathrm{MHz}
$$

and

$$
e Q q_{310}\left({ }^{37} \mathrm{Cl}\right)=+86.51 \mathrm{MHz}
$$

the double bond characters amount to

$$
i_{\pi}=4.2 \% \quad \text { and } \quad i_{\pi}=4.0 \%
$$


for the ${ }^{35} \mathrm{Cl}$ and ${ }^{37} \mathrm{Cl}$ species respectively. The ionic characters are

$$
i_{\sigma}=20.7 \% \text { and } i_{\sigma}=20.9 \% .
$$

As we are aware of the approximative nature of this model, no standard errors are given.

The corresponding mesomeric structures and their importance are:<smiles>[Ge]c1ccncc1</smiles><smiles>Clc1ccncc1</smiles>

II : 218<smiles>O=C1C=CN=CC1=O</smiles><smiles></smiles><smiles></smiles>

The contribution of III is higher in 4-chloropyridine than in chlorobenzene $(3.3 \%$ [15]) or 3 -chloropyridine $(2.9 \%[16])$ but less than the value for 2-chloropyridine (5.4\% [17]).

\section{Acknowledgement}

We thank M. Andolfatto for the preparation of the substance, the members of our group for help and discussion, the Deutsche Forschungsgemeinschaft and Fonds der Chemie for funds. The calculations were made at the computer center of the University of Kiel.

[9] Authors: H. Günter, Tübingen and J. Reinstädtler, Gießen.

11] H. Dreizler, J. Mol. Phys. 57 (1986) to be published.

[2] N. Heineking, H. Dreizler, and R. Schwarz, Z. Naturforsch. 41 a, 1210 (1986).

[3] W. Caminati and P. Forti, Chem. Phys. Lett. 38, 222 (1976).

[4] G. Bestmann, H. Dreizler, H. Mäder, and U. Andresen, Z. Naturforsch. 35a, 392 (1980).

[5] G. Bestmann and H. Dreizler, Z. Naturforsch. 37a, 58 (1982).

[6] G. Bestmann, H. Dreizler, E. Fliege, and W. Stahl, J. Mol. Struct. 97, 215 (1983).

[7] E. Fliege and H. Dreizler, Z. Naturforsch. 39a, 630 (1984).

[8] W. Gordy and R. L. Cook, Microwave Molecular Spectra, John Wiley, New York 1984, Chapt. IX, 5; $\mathrm{XV}, 3$.
10] Authors: D. Hübner and W. Stolze, Kiel.

[11] Author: G. Herberich, Aachen.

[12] C. H. Townes and A. L. Schawlow, Microwave Spectroscopy, McGraw Hill, 1955, p. 244.

[13] l.c. [12], p. 237

[14] 1.c. [8], Table 14.2.

[15] W. Caminati and A. M. Mirri, Chem. Phys. Lett. 12, 127 (1971).

[16] R. D. Brown and J. Matouskova, J. Mol. Struct. 29, 33 (1975).

[17] M. Meyer, Diplom-Thesis, Kiel 1986. 